\title{
Molecular Mapping of Loci Conferring Resistance to Different Pathotypes of the Spot Blotch Pathogen in Barley
}

\author{
H. Bilgic, B. J. Steffenson, and P. M. Hayes
}

First and second authors: Department of Plant Pathology, University of Minnesota, St. Paul 55108; and third author: Department of Crop and

Soil Sciences, Oregon State University, Corvallis 97331.

Accepted for publication 8 February 2006.

\begin{abstract}
Bilgic, H., Steffenson, B. J., and Hayes, P. M. 2006. Molecular mapping of loci conferring resistance to different pathotypes of the spot blotch pathogen in barley. Phytopathology 96:699-708.

Spot blotch, caused by Cochliobolus sativus, is an important disease of barley in many production areas and is best controlled through the deployment of resistant cultivars. Information on the genetics of resistance in various sources can be useful in developing effective breeding strategies. Parents of the doubled haploid mapping population Calicuchima-sib/ Bowman-BC (C/B) exhibit a differential reaction to pathotypes 1 and 2 of C. sativus. To elucidate the genetics of spot blotch resistance in this population, $\mathrm{C} / \mathrm{B}$ progeny were evaluated with both pathotypes at the seedling stage in the greenhouse and at the adult plant stage in the field. At the seedling stage, progeny segregated 84 resistant to 26 susceptible based on the qualitative analysis of infection response (IR) data to pathotype 1 . This fit best to a 3:1 ratio, indicating that two genes were involved in

type 1 revealed a single quantitative trait locus (QTL) on chromosome $4(4 \mathrm{H})$ explaining $14 \%$ of the phenotypic variance. Adult plant resistance to pathotype 1 was conferred by QTL on chromosome $2(2 \mathrm{H})$ and chromosome $3(3 \mathrm{H})$, explaining 21 and $32 \%$ of the phenotypic variation, respectively. Bowman contributed the resistance alleles on chromosome $3(3 \mathrm{H})$ and chromosome $4(4 \mathrm{H})$, whereas Calicuchima-sib contributed the resistance allele on chromosome $2(2 \mathrm{H})$. Resistance to pathotype 2 was conferred by a single gene (designated Rcs 6 ) on chromosome $5(1 \mathrm{H})$ based on qualitative analysis of data. Rcs 6 was effective at both the seedling and adult plant stages and was contributed by Calicuchima-sib. This result was corroborated in the quantitative analysis of raw IR (seedling stage) and disease severity (adult plant stage) data as a single major effect $\left(r^{2}=0.93\right.$ and 0.88 , respectively) QTL was identified on chromosome $5(1 \mathrm{H})$. Progeny with resistance to both pathotypes were identified in the $\mathrm{C} / \mathrm{B}$ population and may be useful in programs breeding for spot blotch resistance.
\end{abstract} conferring resistance. Quantitative analysis of the raw IR data to patho-
One of the most important diseases of barley in the Upper Midwest region of the United States is spot blotch, caused by Cochliobolus sativus (Ito \& Kurib.) Drechs. ex Dastur (anamorph: Bipolaris sorokiniana (Sacc.) Shoem.). Yield losses as high as $35 \%$ have been reported for susceptible barley cultivars under epidemic conditions (8). In the Upper Midwest, spot blotch has been successfully controlled in six-rowed malting cultivars by resistance breeding. This resistance has remained effective for over 40 years and is considered durable (33). In contrast, the resistance of two-rowed feed cultivars like Bowman has been short-lived due to the appearance of virulent $C$. sativus pathotypes (10). At the time of its release in 1984, cv. Bowman was classified as moderately resistant to spot blotch $(10,14)$. However, in 1990 , Bowman and lines derived from it became severely infected with spot blotch in a breeding nursery in eastern North Dakota. This epidemic was caused by a new pathotype of $C$. sativus (10), subsequently designated pathotype 2 (39). Pathotype 2 isolates are widespread throughout the region and threaten two-rowed barley production (39; B. Steffenson, unpublished data). Recent virulence surveys indicate that other potentially damaging pathotypes of $C$. sativus exist in North Dakota (J. D. Franckowiak, personal communication) and neighboring regions of Canada (17). These

Corresponding author: B. J. Steffenson; E-mail address: bsteffen@umn.edu

* The $\boldsymbol{e}$-Xtra logo stands for "electronic extra" and indicates that the online version contains a Table, which is not included in the print edition, showing PCR amplification profiles of SSR primers evaluated to increase marker density in regions of chromosomes $2(2 \mathrm{H})$ and $3(3 \mathrm{H})$ containing spot blotch resistance loci in the Calicuchima-sib/Bowman-BC population.

DOI: 10.1094/PHYTO-96-0699

(C) 2006 The American Phytopathological Society pathotypes carry virulence for some two-rowed lines that were bred for resistance to pathotype 2 . It is clear from these examples that two-rowed cultivars will need to be bred with more broadbased spot blotch resistance if they are to remain commercially competitive in North Dakota and other regions where the disease is a problem.

Calicuchima-sib and Bowman-BC are the parents of a doubled haploid population that was originally developed to map loci conferring resistance to barley stripe rust $(6,21)$. In routine disease evaluations, we found that these parents exhibited a differential response to pathotypes 1 and 2 of $C$. sativus. Bowman-BC is resistant to pathotype 1 and susceptible to pathotype 2, whereas Calicuchima-sib is susceptible to pathotype 1 and resistant to pathotype 2 .

Our long-term goal is to understand the genetic basis of spot blotch resistance in both two- and six-rowed barley so that effective breeding strategies can be developed. The objective of this study was to map loci conferring seedling and adult plant resistance to pathotypes 1 and 2 of C. sativus in the Calicuchima-sib/ Bowman-BC $(\mathrm{C} / \mathrm{B})$ population.

\section{MATERIALS AND METHODS}

Plant material. Calicuchima-sib (selection CMB84A-1127-B$2 \mathrm{~B}-1 \mathrm{Y}-11 \mathrm{M}-0 \mathrm{Y})$ is a six-rowed spring germplasm line that was developed by $\mathrm{H}$. Vivar at the International Center for Agricultural Research in the Dry Areas (ICARDA)/International Maize and Wheat Improvement Center (CIMMYT) barley breeding program based in Mexico. It was derived from the cross LBIran/ UNA8271//Gloria-sib/Comanche-sib and exhibits resistance to the stripe rust (Puccinia striiformis f. sp. hordei), leaf rust (Puccinia hordei), and scald (Rhynchosporium secalis) pathogens in 
production areas of Mexico and the Andean zone of South America $(20,21)$. Bowman (PI 483237) is a two-rowed spring feed type cultivar released by the North Dakota Agricultural Experiment Station in 1984 and traces back to the cross 'Klages'// 'Fergus'/'Nordic'/3/ND1156/4/'Hector' (14). A Bowman backcross-derived line (Bowman-BC) (pedigree of ND586/CIho 2376//ND4880)4*Bowman) carrying the Ryd2 gene for resistance to Barley yellow dwarf virus (BYDV) from CIho 2376 was developed by J. D. Franckowiak at North Dakota State University. A doubled haploid population was developed from the cross $\mathrm{C} / \mathrm{B}$ and used to map loci conferring resistance to stripe rust, leaf rust, scald, and BYDV (20,21). In this study, 110 progeny from the $\mathrm{C} / \mathrm{B}$ population were phenotyped for their reaction to the spot blotch pathogen.

Pathogen isolates and inoculum production. Two pathotypes of C. sativus (isolate ND85F of pathotype 1 and isolate ND90Pr of pathotype 2) were used in this study because they elicited a differential response on Calicuchima-sib and Bowman-BC (Table 1). The pathotype 1 isolate has been used in disease resistance screening tests of barley germplasm at North Dakota State University since 1986, and its virulence pattern is well-established. The pathotype 2 isolate is also used in resistance screening tests because it exhibits a different virulence pattern than pathotype 1 $(10,40)$.

Isolates ND85F and ND90Pr each were originally derived from a different single conidium. The isolates were stored on silica gel crystals in glass vials at $4^{\circ} \mathrm{C}$ (37) until needed for inoculation. To produce inoculum for inoculation, several silica gel crystals with adsorbed conidia were placed in petri dishes containing either yeast peptone soluble starch media (37) or minimal media (36). The cultures were then incubated at $21^{\circ} \mathrm{C}$ with a 12 -h photoperiod (150 to $270 \mu \mathrm{mol}$ photon $\mathrm{m}^{-2} \mathrm{~s}^{-1}$ ). After 2 weeks of incubation, conidia were harvested by adding about $2 \mathrm{ml}$ of distilled water to the plate and then gently scraping the surface of the culture with a rubber spatula. This conidial suspension was filtered through four layers of cheesecloth to remove mycelial fragments and adjusted to the desired concentration based on hemacytometer conidia counts. For the field experiments, inoculum of pathotype 1 was initially produced by spray inoculating the susceptible barley line ND 5883 with the pathotype 1 isolate ND85F. Inoculum $(8,000$ conidia per $\mathrm{ml}$ ) was applied to plants at the booting to early heading stage (growth stage [GS] 41 to 51 on Zadoks' scale [42]) using a boom sprayer pressurized by $\mathrm{CO}_{2}$. At the end of the season, the spot blotch-infected straw of ND 5883 was harvested, bundled, and stored outside until the following spring. This infected barley straw was then used as the pathotype 1 inoculum source for the field experiments. The methods used to produce inoculum of pathotype 2 (isolate ND90Pr) for field inoculations were the same as those described for the greenhouse tests.

Inoculation and disease assessment. For the seedling tests, five seeds each of the parents and progeny were sown in plastic pots $(12.7 \times 12.7 \mathrm{~cm})$ filled with a 50:50 mix of soil/Metro Mix
200 (vermiculite, peat moss, perlite, and sand; Scotts-Sierra Horticultural Products Company, Marysville, $\mathrm{OH}$ ) or a peat moss/ perlite (3:1) potting mix (\#1 Sunshine Mix, Fisons, Vancouver, Canada). The plants were grown at 20 to $22^{\circ} \mathrm{C}$ in a greenhouse with supplemental lighting (150 to $350 \mu \mathrm{mol}$ photon $\mathrm{m}^{-2} \mathrm{~s}^{-1}$ ) provided by sodium vapor lamps for $14 \mathrm{~h} /$ day. Fertilizer was applied at planting with water soluble (15-0-15, N-P-K, $0.2 \mathrm{~g}$ per seedling) and controlled release (14-14-14, N-P-K, $0.1 \mathrm{~g}$ per seedling) formulations. Three differential barley genotypes (ND 5883, ND B112, and Bowman) were also included in the experiment to verify the virulence of the two $C$. sativus pathotypes $(34,40)$. When the second leaves of plants were fully expanded (about 14 days after planting), inoculations were made with a conidial suspension of isolate ND85F or ND90Pr using an atomizer (Model 15, DeVilbiss Health Care Inc., Somerset, PA) pressurized by an air pump $(60 \mathrm{kPa})$. To facilitate the even distribution and adherence of conidia, $10 \mu$ of Tween 20 (polyoxyethylene-20-sorbitan monolaurate) was added for every $100 \mathrm{ml}$ of the inoculum suspension. The spore concentration for inoculation was 6,000 to 7,000 conidia per $\mathrm{ml}$ of double distilled water. Approximately $1 \mathrm{ml}$ of the conidial suspension was applied per plant. After inoculation, plants were placed inside mist chambers maintained near $100 \%$ relative humidity by periodic mistings from ultrasonic humidifiers. During the infection period, plants were kept in complete darkness at $20^{\circ} \mathrm{C}$. After a 16-h infection period, the chamber doors were opened to facilitate the slow drying of the plant surfaces. Then, plants were returned to the greenhouse under the same conditions previously described. Spot blotch infection responses (IRs) were assessed 9 to 11 days postinoculation using the rating scale of Fetch and Steffenson (11). Experiments were conducted in a completely randomized design with one replicate. The evaluations with pathotype 1 were repeated twice in 2000 and once in 2003, whereas the evaluations with pathotype 2 were repeated twice in 2000 .

Parents, progeny, and differential genotypes also were evaluated for spot blotch reaction at the adult plant stage in the field. Evaluations with pathotype 1 (isolate ND85F) were made in 2000, 2001, and 2002 and those with pathotype 2 (isolate ND90Pr) were made in 2000 and 2001. Field tests in 2000 and 2001 were made at the North Dakota Agricultural Experiment Station in Fargo, and those in 2002 were made at the Minnesota Agricultural Experiment Station in St. Paul. In Fargo, the barley entries were sown in hill plots (12 to 15 seeds per hill) spaced $0.3 \mathrm{~m}$ apart in paired rows. In St. Paul, the barley entries were planted in paired $1 \mathrm{~m}$ rows (15 to 25 seeds per row) spaced $0.3 \mathrm{~m}$ apart. The susceptible barley lines ND 5883 and Bowman were planted adjacent to the paired rows of test entries to increase disease development in the pathotype 1 and pathotype 2 nurseries, respectively.

When most of the progeny were at the mid-tillering stage of development (Zadoks GS 24, Zadoks et al. [42]), the susceptible spreader plants of ND 5883 were inoculated with barley straw

TABLE 1. Summary of seedling and adult plant reactions of Calicuchima-sib and Bowman-BC to Cochliobolus sativus pathotypes 1 and 2

\begin{tabular}{|c|c|c|c|c|c|}
\hline & \multicolumn{2}{|c|}{ Seedling } & \multicolumn{3}{|c|}{ Adult } \\
\hline & $\begin{array}{c}\text { Mean of the most } \\
\text { common infection response }^{\mathrm{a}}\end{array}$ & $\begin{array}{c}\text { Range of } \\
\text { infection responses }^{b}\end{array}$ & $\begin{array}{l}\text { Mean severity } \\
\text { and standard error }\end{array}$ & Range in severity ${ }^{d}$ & $\begin{array}{c}\text { Most common } \\
\text { infection response }(\mathrm{s})^{\mathrm{e}}\end{array}$ \\
\hline \multirow[t]{2}{*}{ Pathotype 1} & Calicuchima-sib 5.8 & $5-6$ & $54.1 \pm 21.9 \%$ & $15-75 \%$ & MS-S \\
\hline & Bowman-BC 2.8 & $2-4$ & $18.9 \pm 9.9 \%$ & $10-35 \%$ & MR \\
\hline \multirow[t]{2}{*}{ Pathotype 2} & Calicuchima-sib 2.0 & $2-2$ & $6.5 \pm 3.1 \%$ & $3-12 \%$ & MR-R \\
\hline & Bowman-BC 7.0 & $7-7$ & $52.5 \pm 33.1 \%$ & $25-95 \%$ & $\mathrm{~S}$ \\
\hline
\end{tabular}

a Based on a 1 to 9 scale where 1 is most resistant and 9 is most susceptible (11).

b Lowest and highest infection responses observed on the parents over all experiments.

c Percentage of leaf area affected by disease on a 0 to $100 \%$ scale (34).

${ }^{\mathrm{d}}$ Lowest and highest severity observed on the parents over all experiments.

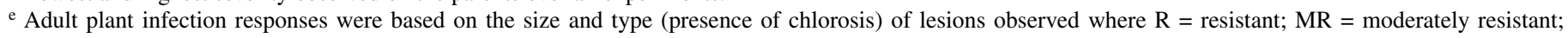
MS = moderately susceptible; and S = susceptible (11). 
infected with the pathotype 1 isolate ND85F (about $50 \mathrm{~g}$ of straw per linear meter of row). This infected barley straw was taken from the previous season's crop at the respective locations. Inoculations with the pathotype 2 isolate ND90Pr were made by foliar application of inoculum $(8,000$ to 10,000 conidia per ml of water applied at $85 \mathrm{ml} / \mathrm{m}^{2}$ ) when the awns of most plants were emerging (Zadoks GS 49). Inoculum was applied to plants with a hand-held boom sprayer with Tee-jet 8002VS nozzles (Bellspray, Inc., Opelousas, CA) pressurized by $\mathrm{CO}_{2}$ at $276 \mathrm{kPa}$. Plants were inoculated during the evening when the environmental conditions were predicted to be favorable for dew formation. To enhance disease levels in the pathotype 2 nursery in 2000, greenhousegrown ND 5883 plants infected with isolate ND90Pr were transplanted into the nursery prior to foliar inoculation. In 2001, disease spread from infected straw in the pathotype 1 nursery was slow; thus, a foliar spray of isolate ND85F was applied to all plants to increase disease levels.

Assessments for disease severity (percentage of leaf area affected by disease from 0 to $100 \%$ ) were made using standard disease area diagrams (34). Disease assessments were made twice during the growing season, three times for late maturing progeny. The terminal disease severity data that were used in quantitative trait loci (QTL) analyses were made at the mid-dough stage of development (Zadoks GS 85 to 86). Adult plant IR assessments were made according to the rating scale of Fetch and Steffenson (11). This IR rating scale consists of four classes (resistant [R], moderately resistant $[\mathrm{MR}]$, moderately susceptible [MS], and susceptible [S]) and is based on lesion size and the degree of associated chlorosis. The experimental design was a randomized complete block with two replications. Pathotype 1 and pathotype 2 disease nurseries were planted over $100 \mathrm{~m}$ apart to reduce possible cross-contamination. Disease responses on the differential barley genotypes confirmed the purity of pathotypes in the respective nurseries.

Addition of new markers to the established molecular map. A molecular map of the C/B population was developed by Chen et al. (7) and later enhanced by the addition of other markers by Castro et al. (6). The most recent C/B map contains a total of 26 restriction fragment length polymorphism (RFLP), 22 simple sequence repeat (SSR), and seven morphological markers (6). The molecular marker data we used for our initial mapping effort contained these 55 markers, plus two additional ones (ABG387C and HVBKASI) not included in the previously published map of Castro et al. (6). Since this map did not provide sufficient resolution for defining QTL conferring spot blotch resistance, we tested a number of additional molecular markers. Seventy-five SSR markers developed by Liu et al. (27), Ramsay et al. (30), Liu and Anderson (26), Thiel et al. (35), and K. P. Smith (personal communication) were screened for polymorphism and then mapped on the C/B population. Additionally, two morphological markers were added to the map: cer-yy controlling the waxy/ glossy spike character and srh controlling rachilla hair length. DNA of the $\mathrm{C} / \mathrm{B}$ progeny and parents were isolated from the leaves of 2-week-old plants according to the methods of SaghaiMaroof et al. (31). Reactions for SSR markers were set up in $25-\mu \mathrm{l}$ volumes and performed in a thermocycler (Research PTC 100 type, MJ Research Inc., Watertown, MA). The polymerase chain reaction (PCR) mixture contained 100 to $150 \mathrm{ng}$ of genomic DNA, $1 \times$ standard PCR buffer, $0.2 \mathrm{mM}$ each dNTP and each primer, $3.0 \mathrm{mM} \mathrm{MgCl}_{2}$, and 1.0 unit of $\mathrm{Taq}$ DNA polymerase (Promega, Madison, WI). PCR cycling profiles were according to Liu et al. (27), Ramsay et al. (30), and Liu and Anderson (26) for their corresponding SSR markers. The cycling conditions applied for marker UMB301 were identical to program $\mathrm{F}$ in Ramsay et al. (30). The following PCR cycles were applied for the UMB201 and UMB302 markers: 9-min initial denaturation at $95^{\circ} \mathrm{C}, 35$ cycles of $10 \mathrm{~s}$ at $94^{\circ} \mathrm{C}, 20 \mathrm{~s}$ at $58^{\circ} \mathrm{C}$, and $45 \mathrm{~s}$ at $72^{\circ} \mathrm{C}$ with a final 2.5-min extension at $72^{\circ} \mathrm{C}$. PCR products were electrophoresed using 3\% GenePure high-resolution agarose gels (ISCBioExpress, Kaysville, UT) according to standard methods. The PCR products were visualized using the GelDoc 2000 gel documentation system (Bio-Rad Laboratories, Hercules, CA).

Linkage and QTL analyses. In preparing the molecular data for QTL analyses in this study, we revised the nomenclature of some markers from the previously published C/B maps $(6,7)$. The first nomenclatural change involved RFLP markers. Thirteen of the previously mapped RFLP loci in this population were given a new or corrected letter designation after comparing their mapping position with the chromosome bin locator of barley genes and markers provided online by the Washington State University, Pullman, barley genomics website. For example, the RFLP marker ksuA1a in the map of Castro et al. (6) was changed to ksuA1C since it mapped to a different bin on chromosome $1(7 \mathrm{H})$ than the previously reported ksuA1A locus on chromosome $1(7 \mathrm{H})$ and the ksuA1B locus on chromosome $7(5 \mathrm{H})$. The second nomenclatural change was for the barley leaf rust resistance gene designated $r P h x$ by Hayes et al. (21). When the proper allelism tests have not been completed, provisional designations of resistance genes should be descriptive of the source of the allele. Thus, $r P h x$ was changed to RphCali-sib pending allelism tests with Rph3, the only leaf rust resistance gene known to lie in proximity with RphCali$s i b$. Finally, the $m v$ locus controlling the two-rowed/six-rowed spike character on chromosome $2(2 \mathrm{H})$ was changed to the proper designation of Vrsl (12).

Linkage analysis and mapping were performed using MapMaker version 2.0 (24) with logarithm of odds (LOD) threshold of 3.0 and theta value of 0.4 . Recombination fractions were converted into map distances using the Kosambi mapping function (22). Linkage groups were assigned using MapMaker's Multipoint/ First Order command with minimum LOD value of 3.0 and maximum theta value of 0.4 . Using the Multipoint/Ripple command, we then computed the likelihood maps arising when the order of all adjacent triples in the current sequence were permuted and confirmed the most likely order for the linkage group being analyzed. Finally, Multipoint/Map was selected to display the maximum likelihood maps of individual linkage groups. In the end, we obtained eight linkage groups in the $C / B$ population, one for each of the known barley chromosomes, except chromosome $3(3 \mathrm{H})$, which was comprised of two linkage groups.

The most common IR observed on the second leaves of plants was averaged over all experiments and used in the QTL analysis of seedling resistance. For QTL analysis of adult plant resistance, the average percent disease severity on flag-2 leaves was used. QTL analyses were performed using QTLCartographer (version 2.0) software (2) with the composite interval mapping (CIM) algorithm (43). Threshold LOD values for declaring significant QTL were determined for each of the four traits (both seedling and adult plant resistance for the two respective pathotypes) using QTLCartographer with 1,000 permutations at $\alpha=0.05$ as suggested by Doerge and Churchill (9). For pathotype 1, permutations resulted in LOD thresholds of 2.50 and 2.75 for seedling and adult plant resistance, respectively. For pathotype 2, a LOD threshold of 2.65 was identified for both seedling and adult plant resistance. Forward-backward regression was done to select cofactors before performing QTL detection by CIM. The standard method (Model 6) with window size of $10.0 \mathrm{cM}$ was selected for CIM analysis. For each QTL, the position and percentage of phenotypic variation explained were estimated. Bin locations of QTL were estimated based on the chromosome bin locator of barley genes and markers available at the Washington State University, Pullman, barley genomics website.

\section{RESULTS}

Addition of new markers and refinement of the established molecular map. The previously published map of $\mathrm{C} / \mathrm{B}$ contained 
A
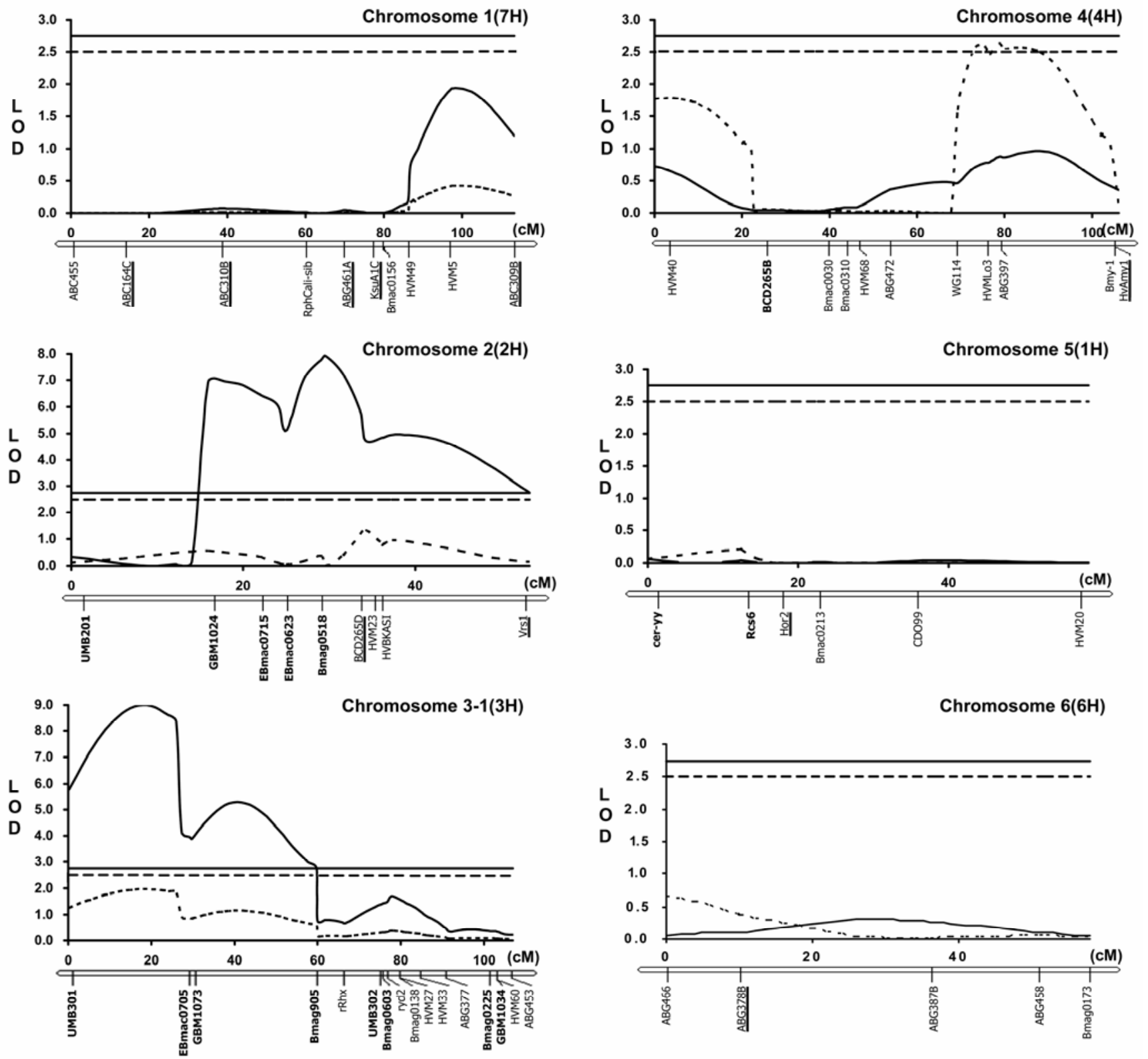

Chromosome 6(6H)
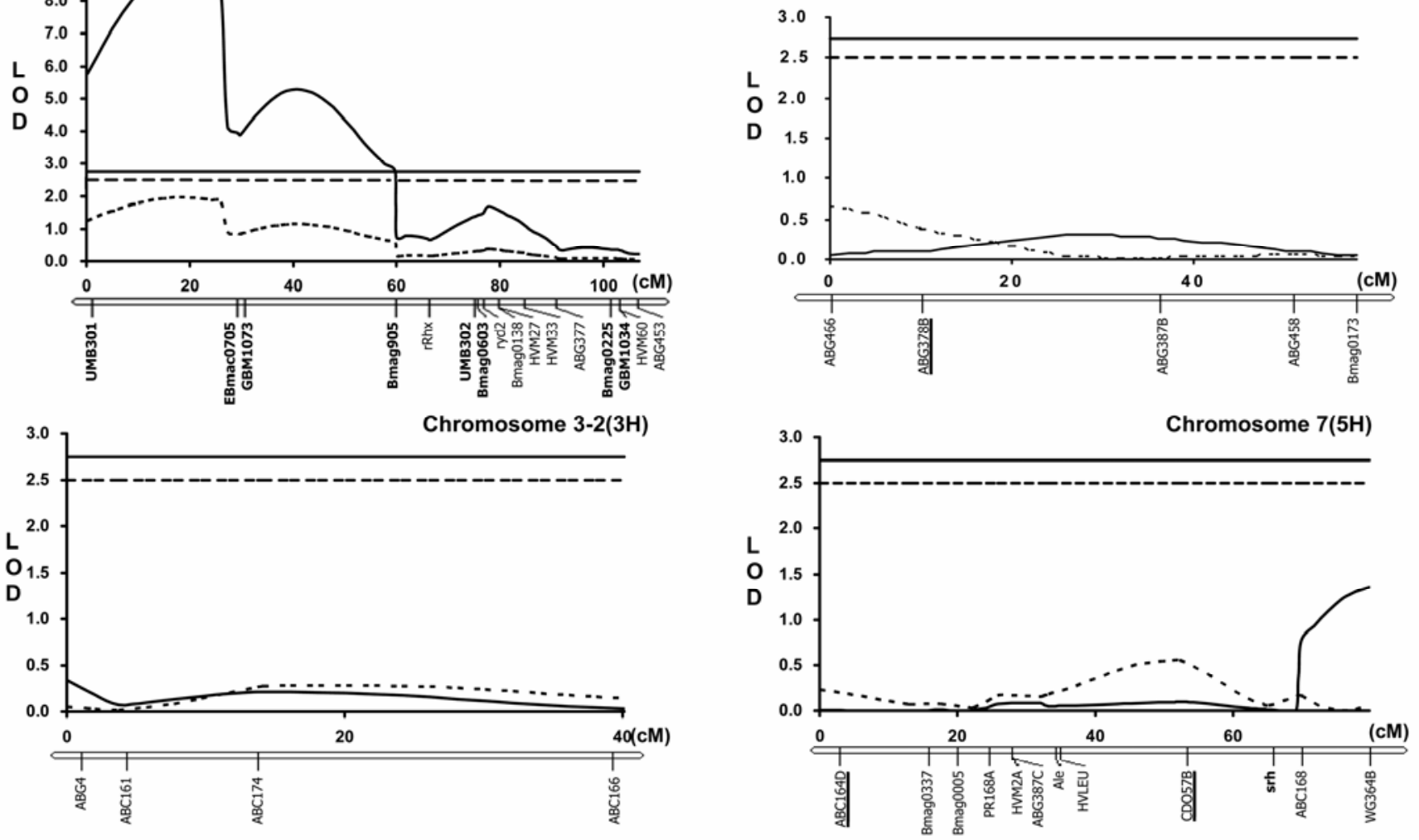

(Continued on next page)

Fig. 1. LOD score profiles of quantitative trait loci (QTL) conferring resistance to A, pathotype 1 and $\mathbf{B}$, pathotype 2 of Cochliobolus sativus in the Calicuchimasib/Bowman-BC population. The plots show the locations of identified QTL based on mean quantitative trait data at the seedling (dashed line) and adult (solid line) plant stages. LOD score scans were obtained by composite interval mapping using QTLCartographer software (2). The threshold LOD values for declaring significant QTL were determined for each of the four traits (both seedling and adult plant resistance for the two respective pathotypes). For pathotype 1, permutations resulted in LOD thresholds of 2.50 and 2.75 for seedling (dashed line) and adult plant (solid line) resistance, respectively. For pathotype 2, a LOD threshold of 2.65 was identified for both seedling and adult plant resistance and is indicated by a solid line. The marker names that were modified from the previously published Calicuchima-sib/Bowman-BC map (6) are underlined. The newly mapped simple sequence repeats and morphological markers are in bold. 
55 molecular markers (6). In this study, we added two morphological markers to the map: cer-yy (controlling the waxy/glossy spike character) on the short arm of chromosome $5(1 \mathrm{H})$ and $s r h$ (controlling rachilla hair length) on the long arm of chromosome

Fig. 1. (Continued from previous page)

B
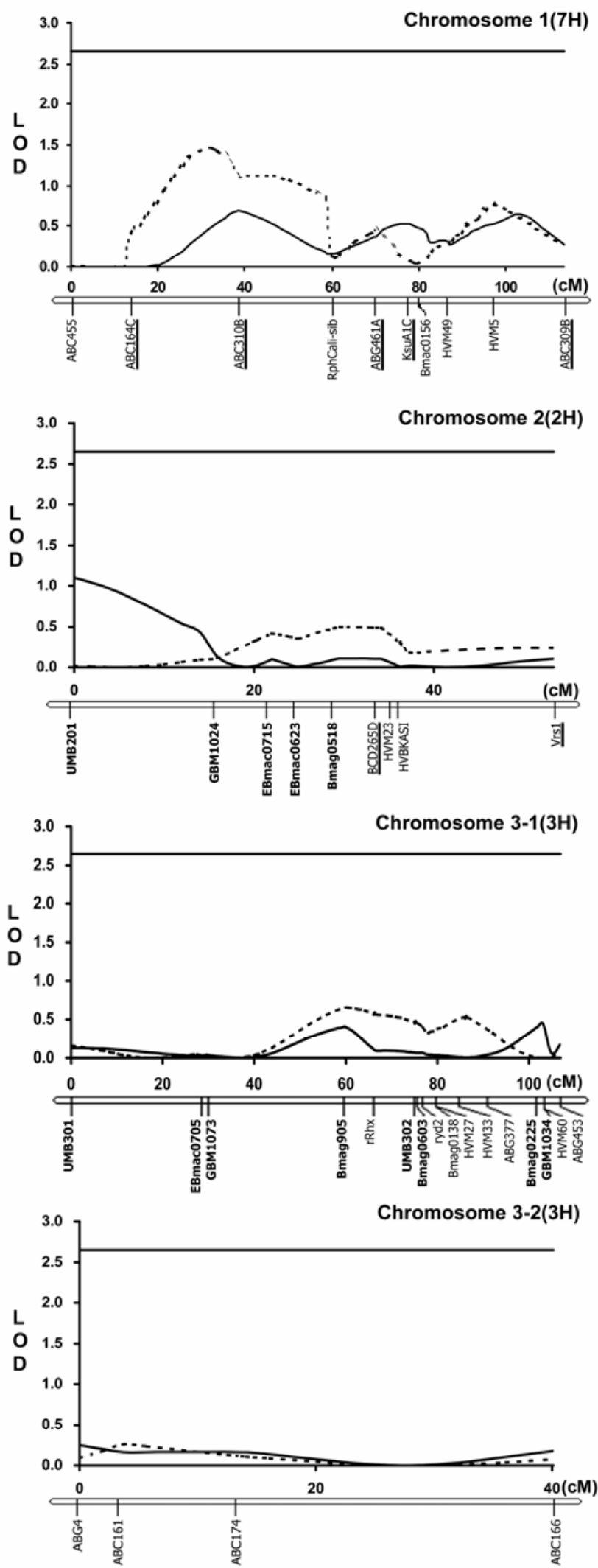

$7(5 \mathrm{H})$. To define more precisely the position of the resistance loci and to possibly join the two linkage groups of chromosome $3(3 \mathrm{H})$, we added other molecular markers to the C/B map. Thirtyfour and forty-one SSR markers were screened on chromosomes
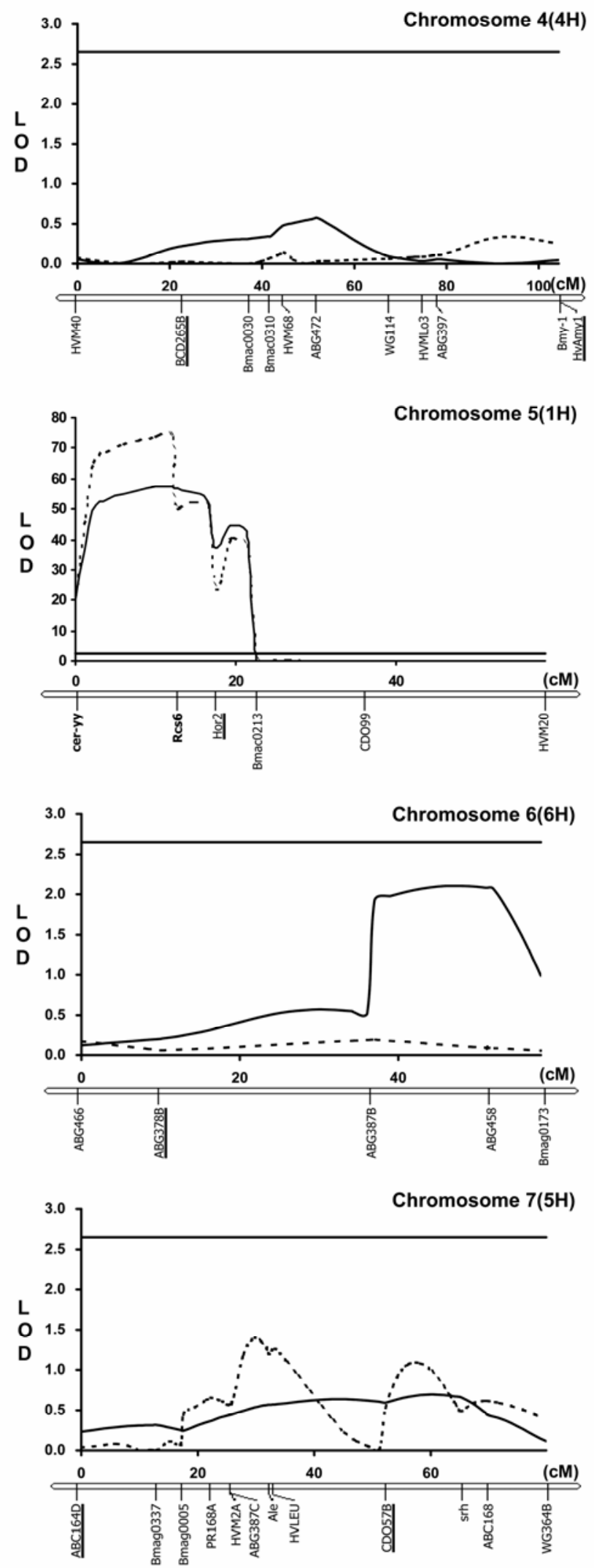
$2(2 \mathrm{H})$ and $3(3 \mathrm{H})$, respectively. The SSR markers were from various origins, including barley and wheat expressed sequence tags (UMB and XSTS3B markers, respectively). Twenty-five of these seventy-five markers were polymorphic in the C/B population (Table 1). We ultimately mapped 13 of these SSR markers around the target regions containing QTL conferring spot blotch resistance. Five of the SSR markers (UMB201, GBM1024, EBmac0715, EBmac0623, and Bmag0518) were mapped on chromosome 2(2H) and eight (UMB301, EBmac0705, GBM1073, Bmag0905, UMB302, Bmag0603, Bmag0225, and GBM1034) were mapped on chromosome $3(3 \mathrm{H})$. All of these SSR markers helped to define with higher resolution the location of QTL conferring resistance. The resulting molecular map of C/B was comprised of eight linkage groups with 73 markers covering $623.9 \mathrm{cM}$. Linkage groups for chromosomes $1(7 \mathrm{H}), 2(2 \mathrm{H}), 4(4 \mathrm{H}), 5(1 \mathrm{H})$, $6(6 \mathrm{H})$, and $7(5 \mathrm{H})$ contained $10,9,11,6,5$, and 12 markers, respectively (Fig. 1). Chromosome $3(3 \mathrm{H})$ was comprised of two linkage groups (chromosome 3-1 and 3-2) with 16 and 4 markers, respectively.

\section{Pathotype 1}

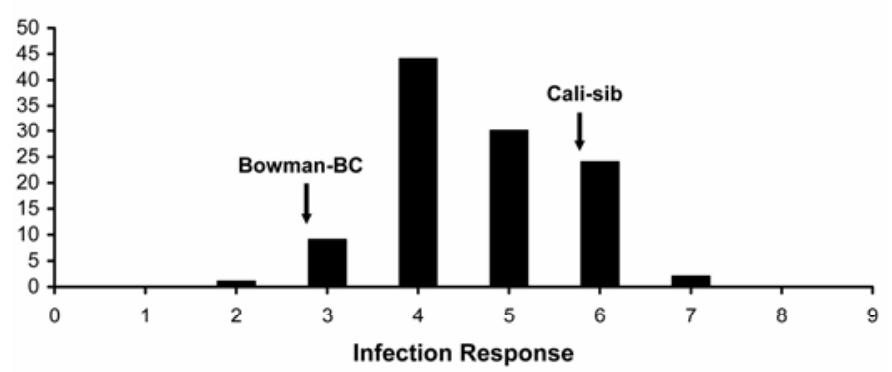

Pathotype 2

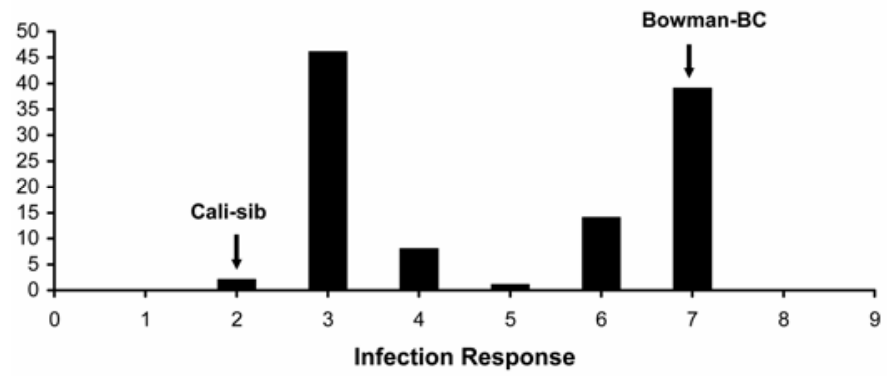

Fig. 2. Frequency distributions for the mean of the most common seedling infection response observed on individual progeny from the Calicuchimasib/Bowman-BC population to pathotypes 1 and 2 of Cochliobolus sativus in the greenhouse.
Genetics of spot blotch resistance at the seedling stage. The IRs exhibited by the respective parents and progeny were similar between experiments. Table 1 summarizes the differential response of the parents to pathotypes 1 and 2 of $C$. sativus. Bowman$\mathrm{BC}$ exhibited low IRs and Calicuchima-sib high to intermediate IRs when infected with pathotype 1 of $C$. sativus. In contrast, Bowman-BC exhibited high IRs and Calicuchima-sib low IRs when infected with pathotype 2 of $C$. sativus. Frequency distributions for the means of the most commonly occurring IRs of $\mathrm{C} / \mathrm{B}$ progeny are given in Figure 2. The distribution pattern to pathotype 1 was continuous, suggesting the presence of multiple genes with minor effects. With pathotype 2 , the distribution pattern was bi-modal, suggesting the presence of a single gene with large effect. To ascertain whether the segregation patterns observed in the $\mathrm{C} / \mathrm{B}$ population followed a Mendelian ratio, progeny were separated into two general categories of resistant or susceptible based on the IR data. Progeny exhibiting IRs 1 through 5 were classified as resistant, and those exhibiting IRs 6 through 9 were classified as susceptible according to the criterion used previously by Steffenson et al. (34). When these qualitative data (i.e., a single locus with two alleles) were subjected to chisquare analysis, different results were obtained in response to the two pathotypes. Segregation of progeny (84 resistant:26 susceptible) in response to pathotype 1 fit best to a two gene (i.e., 3:1) ratio (Table 2). In contrast, segregation of progeny (57 resistant:53 susceptible) in response to pathotype 2 was consistent with a one gene (i.e., 1:1) ratio (Table 2). Using MapMaker, the gene conferring resistance to pathotype 2 was mapped to the ceryy/Hor 2 interval (bins 1 to 2 ) on the short arm of chromosome $5(1 \mathrm{H})$ (Fig. 3), and was given the new locus designation Rcs6 because it maps to a unique location for spot blotch resistance genes. Calicuchima-sib was the donor of this resistance gene.

The mean of the most common IR observed on individual progeny in the $\mathrm{C} / \mathrm{B}$ population was subjected to QTL analysis. Seedling resistance to pathotype 1 was conferred by a single QTL (Rcs-qtl-4H-10-11) mapping to the WG114-ABG397 interval on the long arm of chromosome $4(4 \mathrm{H})$. This QTL, contributed by Bowman-BC, just exceeded the critical LOD value of 2.5 and explained only $14 \%$ of the total phenotypic variation (Table 3; Fig. 1A). Seedling resistance to pathotype 2 was conferred by a single QTL (designated Rcs6-QTL for its coincident position at the previously identified Mendelian locus) mapping to the cer-yyHor2 interval on the short arm of chromosome $5(1 \mathrm{H})$ (Table 3; Fig. 1B). This major effect QTL explained 93\% of the phenotypic variation and was contributed by Calicuchima-sib. The percent phenotypic variation explained, donor parent, peak LOD score, marker interval, and allele value for all QTL conferring seedling resistance are summarized in Table 3.

Genetics of spot blotch resistance at the adult plant stage. Infection levels were moderate to high and mostly uniform on

TABLE 2. Segregation ratios of spot blotch resistant and susceptible progeny from the Calicuchima-sib/Bowman-BC population to pathotypes 1 and 2 of Cochliobolus sativus at the seedling and adult plant stages

\begin{tabular}{|c|c|c|c|c|c|c|c|c|}
\hline & \multicolumn{4}{|c|}{ Seedling } & \multicolumn{4}{|c|}{ Adult } \\
\hline & $\begin{array}{c}\text { Number of } \\
\text { resistant/susceptible progeny }{ }^{\mathrm{a}}\end{array}$ & Ratio fit & $\chi^{2}$ & $P$ value & $\begin{array}{c}\text { Number of } \\
\text { resistant/susceptible progeny }\end{array}$ & Ratio fit & $\chi^{2}$ & $P$ value \\
\hline Pathotype 1 & $84: 26$ & $1: 1$ & 30.58 & 0.000 & $66: 44$ & $1: 1$ & 4.40 & 0.036 \\
\hline Pathotype 2 & $57: 53$ & $1: 1$ & 0.145 & 0.703 & $57: 53$ & $1: 1$ & 0.145 & 0.703 \\
\hline
\end{tabular}

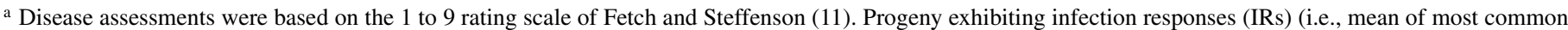

IR observed) from 1 to 5 were classified as resistant and those exhibiting IRs from 6 to 9 were classified as susceptible according the criterion previously used by Steffenson et al. (34).

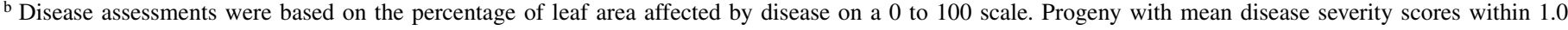
standard deviation of the resistant parent were classified as resistant, and those with mean disease severity scores within 1.0 standard deviation of the susceptible parent were classified as susceptible. Three progeny fell between one standard deviation of the parents and were classified as either susceptible or resistant based on their IRs to pathotype 1 . When the chi-square tests for a one or two gene ratio were performed by excluding these three progeny from data set ( 64 resistant:43 susceptible), the $P$ values fell into the same intervals as presented in Table 2 (66 resistant:44 susceptible). 
entries within each disease nursery. Disease severity did, however, vary from year to year in nurseries as reflected in some of the high standard error values, e.g., for the parents. Calicuchima-sib and Bowman-BC exhibited mean disease severities of $54.1 \pm$ $21.9 \%$ and $18.9 \pm 9.9 \%$, respectively, over replications and years in response to pathotype 1 (Table 1). The corresponding mean disease severities for Calicuchima-sib and Bowman-BC were $6.5 \pm 3.1 \%$ and $52.5 \pm 33.1 \%$ in response to pathotype 2 (Table 1). Frequency distributions for average spot blotch severity of $C / B$ progeny are given in Figure 4. The frequency distribution in response to pathotype 1 was continuous and somewhat bellshaped with a longer tail extending toward the higher severities. This was suggestive of multiple genes with minor effects or possibly gene effects associated with greater environmental variance. In contrast, the frequency distribution in response to pathotype 2 was bi-modal, indicating the presence of a single gene with major effect.

To ascertain whether the segregation pattern observed in the $\mathrm{C} / \mathrm{B}$ population followed a Mendelian ratio, progeny were separated into two general categories of resistant or susceptible based on the mean disease severity scores. Progeny with mean disease severity scores within 1.0 standard deviation of the resistant parent were classified as resistant, and those with mean disease severity scores within 1.0 standard deviation of the susceptible parent were classified as susceptible. The standard deviations of the resistant and susceptible classes did not overlap when the results for pathotype 1 and pathotype 2 were analyzed. However, the average disease severity of three progeny fell between the respective standard deviations of the parents when tested to pathotype 1 . We therefore classified these three progeny into resistant and susceptible classes based on the other disease assessment parameter of IR, which is a component of overall disease severity. Progeny exhibiting IRs of $R$ to MR were classified as resistant, whereas those exhibiting IRs of MS to $\mathrm{S}$ were classified as susceptible. The number of resistant and susceptible (66:44) progeny observed in the $\mathrm{C} / \mathrm{B}$ population to pathotype 1 was not consistent with either a one (i.e., 1:1) or two (i.e., 3:1) gene ratio (Table 2).

QTL analyses were performed on the average disease severity of progeny to determine the number, effect, and chromosome position of loci conferring resistance against pathotype 1. Two adult plant resistance QTL were identified based on CIM analysis: one (Rcs-qtl-3H-1-2) in the UMB301-EBmac0705 interval on the

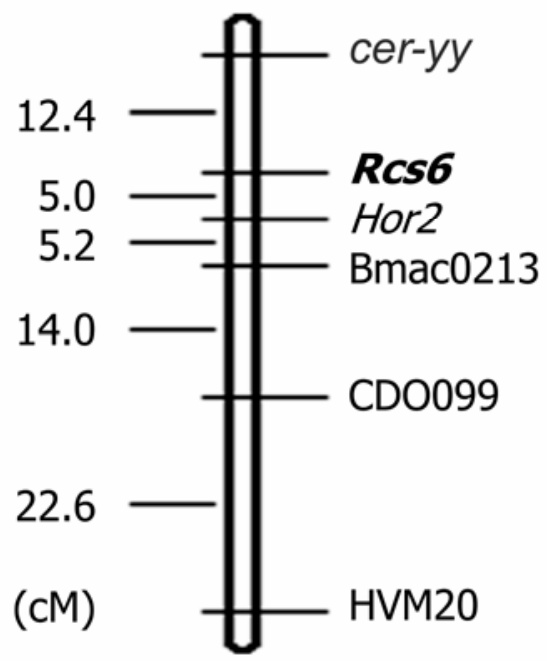

Fig. 3. Linkage map of the short arm of chromosome $5(1 \mathrm{H})$ showing the newly described spot blotch resistance locus Rcs6 (shown in bold) conferring both seedling and adult plant resistance to pathotype 2 of Cochliobolus sativus. Map distances were calculated using the Kosambi function and are shown in centimorgans. short arm of chromosome $3(3 \mathrm{H})$, explaining $32 \%$ of the total variation (contributed by Bowman-BC), and a second (Rcs-qtl$2 H-7-8$ ) in the EBmac0623-BCD265D interval of the centromeric region of chromosome $2(2 \mathrm{H})$, explaining $21 \%$ of the variation (contributed by Calicuchima-sib) (Table 4; Fig. 1A).

The number of resistant and susceptible (57:53) progeny observed in the $\mathrm{C} / \mathrm{B}$ population to pathotype 2 was consistent with a 1:1 segregation ratio, indicating that a single gene confers adult plant resistance (Table 2). All progeny exhibiting resistance at the seedling stage were also resistant at the adult stage; thus, the same gene (Rcs6 contributed by Calicuchima-sib) appears to confer resistance at both growth stages. This result was corroborated from quantitative data analyses as a single adult plant QTL (Rcs6-QTL) was mapped to the same region of chromosome $5(1 \mathrm{H})$ (cer-yy-Hor 2$)$ as the seedling QTL (Rcs6-QTL) and explained a very high percentage $(88 \%)$ of the variation (Table 4; Fig. 1B).

TABLE 3. Summary of quantitative trait loci (QTL) conferring resistance to pathotypes 1 and 2 of Cochliobolus sativus at the seedling stage in the Calicuchima-sib/Bowman-BC population

\begin{tabular}{ccc}
\hline \multicolumn{1}{c}{ QTL } & Rcs-qtl-4H-10-11 & $R c s 6-Q T L$ \\
\hline Pathotype 1 & & \\
\% Variation explained & $14 \%$ & $-^{\mathrm{a}}$ \\
Donor parent & Bowman-BC & \\
Peak LOD value & 2.64 & \\
Peak LOD interval & WG114 to ABG397 & \\
Additive effect & -0.24 & \\
\% Variation explained & & $93 \%$ \\
Donor parent & $-{ }^{\mathrm{a}}$ & Calicuchima-sib \\
Peak LOD value & & 73.9 \\
Peak LOD interval & & cer-yy to Hor 2 \\
Additive effect & & -22.91 \\
\hline
\end{tabular}

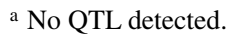

Pathotype 1
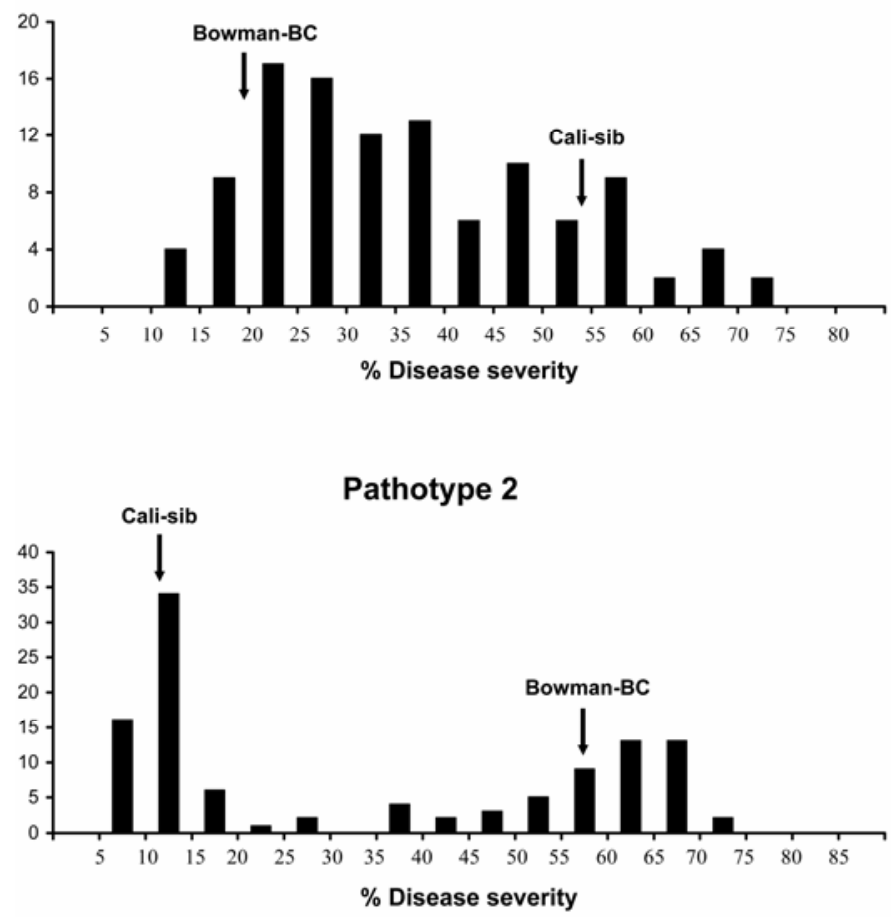

Fig. 4. Frequency distributions for the average disease severity on adult plants of individual progeny from the Calicuchima-sib/Bowman-BC population to pathotypes 1 and 2 of Cochliobolus sativus in the field. 


\section{DISCUSSION}

Our long-term goal is to understand the genetic basis of spot blotch resistance in both two- and six-rowed barley so that effective breeding strategies can be developed. In this study, we characterized the genetics of seedling and adult plant resistance in a barley population $(\mathrm{C} / \mathrm{B})$ whose parents (the six-rowed Calicuchima-sib and two-rowed Bowman-BC) differed markedly in their reaction to different pathotypes of the spot blotch pathogen. One of the pathotypes (pathotype 1) exhibits low virulence on cv. Bowman and was originally used to select for spot blotch resistance during Bowman's development, and the second (pathotype 2) was isolated from compatible lesions on severely infected plants of Bowman in the field. In contrast, pathotypes 1 and 2 exhibit high and low virulence, respectively, on Calicuchima-sib.

Seedling resistance in the $\mathrm{C} / \mathrm{B}$ population was studied under the controlled conditions of the greenhouse. Qualitative analysis of IR data indicated that two genes were involved in conferring resistance to pathotype 1 (Table 2). This result is in agreement with two previous studies exploring the resistance of Bowman to pathotype 1 isolates $(18,38)$. In contrast, quantitative analysis of the raw IR data revealed just a single QTL, Rcs-qtl-4H-10-11, contributed by Bowman-BC (Table 3; Fig. 1A). These contrasting results were due to several factors. First, the two analyses employed completely different statistical methods. Second, they were based on markedly different forms of the IR data-a twoclass data set for the Mendelian analysis and the raw 1-to-9 IR scores for the QTL analysis. Other possible factors for the discrepancy in the results include the density of the molecular map and the size of the segregating population used in QTL analysis. It is possible that other QTL may be present in regions of the genome that are sparsely mapped, but were not detected due to the low density of markers. Population size also can be important in QTL detection (3). Estimates of QTL effect and location are subject to error when the population size is small (i.e., <200) (3). Obviously, better resolution for QTL detection/estimation could be obtained from more saturated maps of larger populations, but this would be offset by significantly greater costs. To pathotype 2 , seedling resistance in the $\mathrm{C} / \mathrm{B}$ population was conferred by a single gene (designated Rcs 6 ) contributed by Calicuchima-sib. The results we obtained from the qualitative data analysis also were corroborated from quantitative data analysis as a single large effect QTL $\left(r^{2}=0.93\right)$ was mapped to the Rcs6 region of chromosome 5(1H) (Table 3; Fig. 1B). All progeny carrying Rcs6 were also resistant as adult plants in the field. Thus, Rcs 6 effectively confers both seedling and adult plant resistance.

Durability is an important aspect in breeding barley for spot blotch resistance in the Upper Midwest region. In this regard, adult plant resistance is of paramount importance because the

TABLE 4. Summary of quantitative trait loci (QTL) conferring resistance to pathotypes 1 and 2 of Cochliobolus sativus at the adult stage in the Calicuchima-sib/Bowman-BC population

QTL Rcs-qtl-2H-7-8 Rcs-qtl-3H-1-2 Rcs6-QTL

Pathotype 1
$\%$ Variation explained Donor parent Peak LOD value Peak LOD interval

$21 \%$ Cali-sib 7.92 to BCD265D $+7.19$

$$
\begin{gathered}
32 \% \\
\text { Bowman-BC } \\
9.00 \\
\text { UMB301 to } \\
\text { EBmac0705 } \\
-8.67
\end{gathered}
$$

Additive effect

$-\mathrm{a}$

$\%$ Variation explained

Donor parent

Peak LOD interval

Additive effect

a No QTL detected. EBmac0623

Peak LOD value disease usually becomes severe after the plants have headed. The adult plant resistance of Midwestern six-rowed malting cultivars is durable and has remained effective for over 40 years (34). In contrast, spot blotch resistance in the Midwestern two-rowed cv. Bowman was short-lived, succumbing to a virulent pathotype of C. sativus after only 6 years of cultivation (10). Analysis of adult plant resistance to pathotype 1 in the $\mathrm{C} / \mathrm{B}$ population revealed two QTL: one on chromosome $2(2 \mathrm{H})$ contributed by Calicuchima-sib and a second on chromosome $3(3 \mathrm{H})$ contributed by Bowman-BC (Table 4; Fig. 1A). The resistance allele contributed by Bowman$\mathrm{BC}$ on chromosome $3(3 \mathrm{H})$ explained $32 \%$ of the phenotypic variation, but was not effective against pathotype 2 isolates of C. sativus. Valjavec-Gratian (38) studied the genetics of adult plant resistance in Bowman to pathotype 1. Although data from the $F_{2}$ generation were not in complete agreement with those obtained in the $F_{2: 3}$, the overall results suggested the presence of one or two genes. Thus, it appears that the adult plant resistance of Bowman to pathotype 1 is controlled by one or possibly two genes. Valjavec-Gratian and Steffenson (40) also investigated the genetics of host-specific virulence in a $C$. sativus cross between a pathotype 2 isolate (ND90Pr) with high virulence on Bowman and a pathotype 0 isolate (ND93-1) with low virulence on Bowman. They found that a single gene in isolate ND90Pr conferred virulence on Bowman at the seedling stage. This result suggests that simple genetic changes may be sufficient to overcome adult plant resistance in Bowman.

If two-rowed cultivars like Bowman are to remain competitive in the Dakotas, they must be bred with broad-based resistance to spot blotch. During the advent of the two-rowed barley improvement program at North Dakota State University, Midwestern sixrowed barley cultivars were used in crossing to transfer important traits for adaptation and also resistance to important diseases such as stem rust (Puccinia graminis f. sp. tritici) and spot blotch (13). Unfortunately, these crosses failed to yield superior breeding lines or cultivars carrying the durable spot blotch resistance conferred by the chromosome $5(1 \mathrm{H})$ QTL in six-rowed barley (34). Even if this QTL had been transferred into a two-rowed background, there is no guarantee that it would confer durable resistance or even be expressed at all. Bilgic et al. (4) recently demonstrated how the chromosome 5 $(1 \mathrm{H})$ QTL first identified in the Steptoe/ Morex population (34) was completely suppressed when introgressed into more diverse two- or six-rowed genetic backgrounds (e.g., Harrington/Morex and Dicktoo/Morex populations). Thus, one cannot predict a priori whether spot blotch resistance will be expressed in certain genetic backgrounds, let alone prove durable. In breeding for broad-based spot blotch resistance, it is important to rigorously evaluate breeding lines over several locations and years. Additionally, this germplasm also should be tested against the full spectrum of pathogen virulence types present in the region. In addition to pathotype 2, which threatens two-rowed barley production in the region (39; B. Steffenson, unpublished data), there is evidence for other potentially damaging pathotypes of C. sativus in North Dakota (J. D. Franckowiak, personal communication) and western Canada (17).

Previously published studies reported seven different Mendelian loci for resistance to spot blotch in barley (Rcs 1 to $R \operatorname{cs} 5$ plus two unnamed ones) and one QTL as summarized by Bilgic et al. (4), Søgaard and von Wettstein-Knowles (32), and Steffenson et al. (34). Rcs 1, Rcs 2, and Rcs 3 were postulated to lie on chromosomes $2(2 \mathrm{H}), 5(1 \mathrm{H})$, and $7(5 \mathrm{H})$, respectively, by their loose association with various morphological markers (19). The designation of Rcs 4 is based on the genetic data of Arny (1), but no information was obtained with regard to its chromosomal location. Steffenson et al. (34) described and mapped Rcs5 on chromosome 1(7H). Two other Mendelian resistance loci were identified in Bowman by Gonzalez Ceniceros (18). They were associated with the $g s h 2$ (formerly $g s 2$ ) locus on chromosome $3(3 \mathrm{H})$ and vrs 3 (formerly v3) locus on chromosome $5(1 \mathrm{H})$, respectively. Recently, Bilgic et
$88 \%$ 
al. (4) identified three new loci for spot blotch resistance after comparing the positions of marker loci with several barley consensus maps $(12,25,29)$ : one $(R c s-q t l-7 H-7)$ conferring seedling resistance at the centromeric region of chromosome $1(7 \mathrm{H})$, a second (Rcs-qtl-2H-3-5) conferring adult plant resistance on the short arm of chromosome $2(2 \mathrm{H})$, and a third (Rcs-qtl-3H-2-6) conferring seedling and adult plant resistance on the short arm of chromosome $3(3 \mathrm{H})$.

In this study, we identified two new spot blotch resistance loci (Rcs6 and Rcs-qtl-4H-10-11) based on the positions of marker loci on the barley consensus maps and the postulated chromosomal positions of loci reported by other researchers $(4,18,19,34)$. Rcs6 maps to the short arm of chromosome $5(1 \mathrm{H})$ and confers resistance to pathotype 2 at both the seedling and adult plant stages. Rcs-qtl-4H-10-11 maps to chromosome $4(4 \mathrm{H})$ and confers resistance to pathotype 1 at the seedling stage. Although these two loci map to unique locations for Rcs genes and QTL, their chromosomal positions do coincide with other disease resistance genes. Rcs6 maps to the distal end of the short arm of chromosome $5(1 \mathrm{H})$ where loci for resistance to powdery mildew (Blumeria graminis f. sp. hordei) (41), leaf scald $(15,16,41)$, and leaf rust (28) were previously described. Rcs-qtl-4H-10-11 maps to the same general region where Castro et al. $(5,6)$ reported stripe rust resistance loci in the $\mathrm{C} / \mathrm{B}$ and Shyri/Galena populations. Yun et al. (41) also reported a QTL for powdery mildew resistance in this same region. This general region of chromosome $4(4 \mathrm{H})$ contains the powdery mildew resistance locus $m l o$, which is known to have pleiotropic effects with other fungal pathogens infecting barley, including $C$. sativus (23). Based on pedigree analysis, the parents used in this investigation probably do not carry mlo. However, future studies should be made to verify this and the exact chromosomal location of Rcs-qtl-4H-10-11 in relation to the mlo locus. The other QTL identified in this study (Rcs-qtl-2H-78) appears to map in a genomic region where Griffee (19) and Bilgic et al. (4) reported loci for spot blotch resistance. It is difficult to state with certainty whether this QTL is allelic with those previously reported. Additional tests will be required to resolve this question.

In this study, we refined the latest $\mathrm{C} / \mathrm{B}$ map of Castro et al. (6) by adding 13 new SSR and two morphological markers. The current $\mathrm{C} / \mathrm{B}$ map now contains a total of 73 markers across eight linkage groups covering $623.9 \mathrm{cM}$ in map distance (Fig. 1). The $\mathrm{C} / \mathrm{B}$ population has been very useful for resolving traits such as disease resistance (stripe rust, leaf rust, scald, and BYDV). The refined map developed in this study may prove useful for future genetic studies on traits of agronomic importance and for mining the multiple resistance genes pyramided in these barley genotypes by H. Vivar (ICARDA/CIMMYT, retired) and J. Franckowiak (North Dakota State University).

Deployment of resistant cultivars is the most economic and environmentally sound means of preventing epidemics of spot blotch. In this study, we obtained information that will have practical implications for barley breeding programs in the Upper Midwest region and beyond. We identified a gene (Rcs6 from Calicuchima$\mathrm{sib}$ ) for resistance to pathotype 2 isolates that can be used in addition to $R \operatorname{cs} 5$ and the chromosome 5(1H) QTL, which are found in six-rowed malting types. Second, we identified several two-rowed progeny that carry resistance to both pathotypes of $C$. sativus. These progeny will be valuable in two-rowed programs breeding for spot blotch resistance. Utilization of molecular markers flanking the identified resistance loci will increase the selection efficiency for identifying progeny with broad-based resistance.

\section{ACKNOWLEDGMENTS}

This research was supported in part by the United States Barley Genome Project (formerly North American Barley Genome Project), American Malting Barley Association, and the Lieberman-Okinow En- dowment at the University of Minnesota. We thank K. P. Smith for providing the SSR primers for testing; H. Vivar (ICARDA/CIMMYT, retired) and J. Franckowiak (North Dakota State University) for developing and sharing the Calicuchima-sib and Bowman-BC parental lines with us; and T. Szinyei for assistance in preparing the figures.

\section{LITERATURE CITED}

1. Arny, D. C. 1951. Inheritance of resistance to spot blotch in barley seedlings. Phytopathology 41:691-698.

2. Basten, J. C., Weir, B. S., and Zeng, Z.-B. 2001. QTL Cartographer: A reference manual and tutorial for QTL mapping. North Carolina State University, Raleigh.

3. Bernardo, R. 2002. Pages 303-307 in: Breeding for Quantitative Traits in Plants. Stemma Press, Woodbury, MN.

4. Bilgic, H., Steffenson, B. J., and Hayes, P. M. 2005. Comprehensive genetic analyses reveal differential expression of seedling and adult plant resistance to spot blotch in populations of barley. Theor. Appl. Genet. 111:1238-1250.

5. Castro, A. J., Chen, X., Hayes, P. M., Knapp, S. J., Line, R. F., Toojinda, T., and Vivar, H. 2002. Coincident QTL which determine seedling and adult plant resistance to stripe rust in barley. Crop Sci. 42:1701-1708.

6. Castro, A., Hayes, P. M., Fillichkin, T., and Rossi, C. 2002. Update of barley stripe rust resistance QTL in the Calicuchima-sib $\times$ Bowman mapping population. Barley Genet. Newsl. 32:1-12.

7. Chen, F. Q., Prehn, D., Hayes, P. M., Mulrooney, D., Corey, A., and Vivar, H. 1994. Mapping genes for resistance to barley stripe rust (Puccinia striiformis f. sp. hordei). Theor. Appl. Genet. 88:215-219.

8. Clark, R. V. 1979. Yield losses in barley cultivars caused by spot blotch. Can. J. Plant Pathol. 1:113-117.

9. Doerge, R. W., and Churchill, G. A. 1996. Permutation test for multiple loci affecting a quantitative character. Genetics 142:285-294.

10. Fetch, T. G., Jr., and Steffenson, B. J. 1994. Identification of Cochliobolus sativus isolates expressing differential virulence on two-rowed barley genotypes from North Dakota. Can. J. Plant Pathol. 16:202-206.

11. Fetch, T. G., Jr., and Steffenson, B. J. 1999. Rating scales for assessing infection responses of barley infected with Cochliobolus sativus. Plant Dis. 83:213-217.

12. Franckowiak, J. D. 1997. Revised linkage maps for morphological markers in barley, Hordeum vulgare. Barley Genet. Newsl. 26:9-21.

13. Franckowiak, J. D. 2001. Accumulating genes for disease resistance in two-rowed barley for North Dakota. Pages 39-46 in: Breeding Barley in the New Millennium, Proceedings of an International Symposium. H. E. Vivar and $\mathrm{A}$. McNab, eds. International Maize and Wheat Improvement Center (CIMMYT), Mexico, D.F.

14. Franckowiak, J. D., Foster, A. E., Pederson, V. D., and Pyler, R. E. 1985. Registration of Bowman barley. Crop Sci. 25:883.

15. Garvin, D. F., Brown, A. H. D., Raman, H., and Read, B. J. 2000. Genetic mapping of the barley Rrs 14 scald resistance gene with RFLP, isozyme and seed storage protein markers. Plant Breed. 119:193-196.

16. Genger, R. K., Williams, K. J., Raman, H., Read, B. J., Wallwork, H., Burdon, J. J., and Brown, A. H. D. 2003. Leaf scald resistance genes in Hordeum vulgare and Hordeum vulgare sp. spontaneum: Parallels between cultivated and wild barley. Austr. J. Agric. Res. 54:1335-1342.

17. Ghazvini, H., and Tekauz, A. 2004. Population structure of Bipolaris sorokiniana in western Canada. Pages 768-773 in: Proc. 9th Int. Barley Genetics Symp. J. Spunar and J. Janikova, eds. Agricultural Research Institute-Kromeriz Ltd., Brno, Czech Republic.

18. Gonzalez Ceniceros, F. 1990. Assigning genes conferring resistance to spot and net blotch in barley to a specific chromosome. Ph.D. diss. North Dakota State University, Fargo.

19. Griffee, F. 1925. Correlated inheritance of botanical characters in barley, and manner of reaction to Helminthosporium sativum. J. Agric. Res. 30:915-935.

20. Hayes, P. M., Corey, A. E., Dovel, R., Karow, R., and Rhinart, K. 1998. Registration of 'Orca' Barley. Oregon Agric. Exp. Stn. Manuscript No. 11528 Registration by CSSA.

21. Hayes, P. M., Prehn, D., Vivar, H., Blake, T., Comeau, A., Henry, I., Johnston, M., Jones, B., Steffenson, B., St. Pierre, C. A., and Chen, F. 1996. Multiple disease resistance loci and their relationship to agronomic and quality loci in a spring barley population. J. Agric. Genomics, Vol. 2. (Published with permission from CABI International (http://www.cabipublishing.org/JAG).

22. Kosambi, D. D. 1944. The estimation of map distances from recombination values. Ann. Eugenet. 12:172-175.

23. Kumar, J., Hückelhoven, R., Beckhove, U., Nagarajan, S., and Kogel, K.H. 2001. A compromised Mlo pathway affects the response of barley to the necrotrophic fungus Bipolaris sorokiniana (teleomorph: Cochliobolus sativus) and its toxins. Phytopathology 91:127-133. 
24. Lander, E. S., Green, P., Abrahamson, J., Barlow, A., Daly, M. J., Lincoln, S. E., and Newburg, L. 1987. MAPMAKER: An interactive computer package for constructing primary genetic linkage maps of experimental and natural populations. Genomics 1:174-181.

25. Langridge, P., Karakousis, A., Collins, N., Kretchmer, J., and Manning, S. 1995. A consensus linkage map of barley. Mol. Breed. 1:389-395.

26. Liu, S., and Anderson, J. A. 2003. Targeted molecular mapping of a major wheat QTL for Fusarium head blight resistance using wheat ESTs and syntheny with rice. Genome 46:817-823.

27. Liu, Z.-W., Biyashev, R. M., and Saghai-Maroof, M. A. 1996. Development of simple sequence repeat DNA markers and their integration into a barley linkage map. Theor. Appl. Genet. 93:869-876.

28. McDaniel, M. E., and Hathcock, B. R. 1969. Linkage of the Pa4 and Mla loci in barley. Crop Sci. 9:822.

29. Qi, X., Stam, P., and Lindhout, P. 1996. Comparison and integration of four barley genetic maps. Genome 39:379-394.

30. Ramsay, L., Macaulay, M., degli Ivanissevich, S., MacLean, K., Cardle, L., Fuller, J., Edwards, K. J., Tuvesson, S., Morgante, M. Massari, A., Maestri, E., Marmiroli, N., Sjakste, T., Ganal, M., Powell, W., and Waugh, R. 2000. A simple sequence repeat-based linkage map of barley. Genetics 156:1997-2005.

31. Saghai-Maroof, M. A., Solima, K. M., Jorgenson, R. A., and Allard, R. W. 1984. Ribosomal DNA spacer-length polymorphisms in barley: Mendelian inheritance, chromosomal location, and population dynamics. Proc. Natl. Acad. Sci. USA 81:8014-8018.

32. Søgaard, B., and von Wettstein-Knowles, P. 1987. Barley: Genes and chromosomes. Carlsberg Res. Commun. 52:123-196.

33. Steffenson, B. J. 2000. Durable resistance to spot blotch and stem rust in barley. Pages 39-44 in: Proc. 8th Int. Barley Genetics Symp. (Barley
Genetics VIII, Vol. I) S. Logue, ed. Adelaide University, Glen Osmond, South Australia.

34. Steffenson, B. J., Hayes, P. M., and Kleinhofs, A. 1996. Genetics of seedling and adult plant resistance to net blotch (Pyrenophora teres f. teres) and spot blotch (Cochliobolus sativus) in barley. Theor. Appl. Genet. 92:552-558.

35. Thiel, T., Michalek, W., Varshney, R. K., and Graner, A. 2003. Exploiting EST databases for the development and characterization of gene-derived SSR-markers in barley (Hordeum vulgare L.). Theor. Appl. Genet. 106:411-422.

36. Tinline, R. D. 1960. Pathogenic and cultural variation in Cochliobolus sativus. Trans. Br. Mycol. Soc. 43:696-697.

37. Tuite, J. 1969. Plant Pathological Methods. Burgess Publishing Co., Minneapolis, MN.

38. Valjavec-Gratian, M. 1996. Genetics of resistance and virulence in the Hordeum vulgare: Cochliobolus sativus pathosystem. Ph.D. diss. North Dakota State University, Fargo.

39. Valjavec-Gratian, M., and Steffenson, B. J. 1997. Pathotypes of Cochliobolus on barley. Plant Dis. 81:1275-1278.

40. Valjavec-Gratian, M., and Steffenson, B. J. 1997. Genetics of virulence in Cochliobolus sativus and resistance in barley. Phytopathology 87:11401143.

41. Yun, S. J., Gyenis, L., Hayes, P. M., Smith, K. P., Steffenson, B. J., and Muehlbauer, G. J. 2005. Identification of quantitative trait loci for multiple disease resistance in wild barley. Crop Sci. 45:2563-2572.

42. Zadoks, J. C., Chang, T. T., and Koznak, C. F. 1974. A decimal code for the growth stages of cereals. Weed Res. 14:415-421.

43. Zeng, Z.-B. 1994. Precision mapping of quantitative trait loci. Genetics $136: 1457-1468$ 